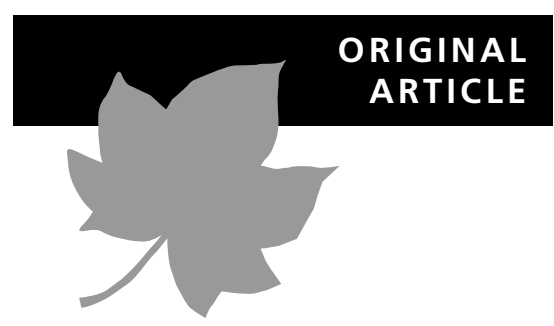

\title{
The relative importance of environment, human activity and space in explaining species richness of South African bird orders
}

John W. Wilson ${ }^{1}$, Berndt J. van Rensburg ${ }^{1,2 \star}$, J. Willem H. Ferguson ${ }^{1,3}$ and Mark Keith ${ }^{1,4}$

${ }^{1}$ Department of Zoology and Entomology, ${ }^{2}$ Centre for Invasion Biology, ${ }^{3}$ Centre for Environmental Studies and ${ }^{4}$ Mammal Research Institute, University of Pretoria, Pretoria 0002, South Africa
${ }^{*}$ Correspondence: Berndt J. van Rensburg, Department of Zoology and Entomology, University of Pretoria, Pretoria 0002, South Africa.

E-mail: bjvanrensburg@zoology.up.ac.za

\begin{abstract}
Aim To assess the relative importance of environmental (climate, habitat heterogeneity and topography), human (population density, economic prosperity and land transformation) and spatial (autocorrelation) influences, and the interactions between these predictor groups, on species richness patterns of various avifaunal orders.
\end{abstract}

Location South Africa.

Methods Generalized linear models were used to determine the amount of variation in species richness, for each order, attributable to each of the different predictor groups. To assess the relationships between species richness and the various predictor groups, a deviance statistic (a measure of goodness of fit for each model) and the percentage deviation explained for the best fitting model were calculated.

Results Of the 12 avifaunal orders examined, spatially structured environmental deviance accounted for most of the variation in species richness in 11 orders (averaging 28\%), and $50 \%$ or more in seven orders. However, orders comprising mostly water birds (Charadriiformes, Anseriformes, Ciconiformes) had a relatively large component of purely spatial deviance compared with spatially structured environmental deviance, and much of this spatial deviance was due to higher-order spatial effects such as patchiness, as opposed to linear gradients in species richness. Although human activity, in general, offered little explanatory power to species richness patterns, it was an important correlate of spatial variation in species of Charadriiformes and Anseriformes. The species richness of these water birds was positively related to the presence of artificial water bodies.

Main conclusions Not all bird orders showed similar trends when assessing, simultaneously, the relative importance of environmental, human and spatial influences in affecting bird species richness patterns. Although spatially structured environmental deviance described most of the variation in bird species richness, the explanatory power of purely spatial deviance, mostly due to nonlinear geographical effects such as patchiness, became more apparent in orders representing water birds. This was especially true for Charadriiformes, where the strong anthropogenic relationship has negative implications for the successful conservation of this group.

\section{Keywords}

Avifaunal orders, environmental factors, human activities, macroecology, patchiness, South Africa, spatial autocorrelation, water birds. 


\section{INTRODUCTION}

Today, the distribution and diversity of life at intermediate scales covary mainly with the geographical patterns of two main groups of explanatory variables: anthropogenic activities (e.g. land transformation, Gaston, 2005) and environmental variables (e.g. energy availability, Currie, 1991; O’Brien, 1998; Gaston, 2000). Although human population dynamics and resource demands contribute most to recent changes in the spatial patterns of biodiversity (Gaston, 2005), studies often neglect the influence of human activity. For example, few studies incorporate factors such as human population growth, advancement and development into model building (e.g. systematic conservation planning models, Margules \& Pressey, 2000; Gaston et al., 2001) or studies relating to ecosystem functioning (McDonnell \& Pickett, 1990; O’Neill \& Kahn, 2000; Fairbanks et al., 2002). Neglecting the effects of anthropogenic activity on biodiversity's geographical patterns could therefore jeopardize our understanding of the mechanisms that account for changes in environmental variables and that translate into altered species richness patterns.

Species richness patterns are also influenced by the species richness of surrounding areas, because species richness tends to be spatially autocorrelated (Legendre \& Fortin, 1989; Borcard et al., 1992; Legendre, 1993; Schiegg, 2003). Similarly, as the distribution patterns of birds are affected by environmental, biological and anthropogenic factors, the spatial structure present in those factors may also have spill-over effects on species richness patterns (Legendre \& Fortin, 1989; Legendre \& Legendre, 1998; van Rensburg et al., 2002; Diniz-Filho et al., 2003). The assumption of data independence in statistical techniques therefore rarely holds in examinations of broadscale biodiversity patterns (spatial autocorrelation, Legendre \& Fortin, 1989; Borcard et al., 1992; Legendre, 1993; Schiegg, 2003), and spatial autocorrelation in ecological data must be accounted for when attempting to understand the mechanisms driving species' biogeographical patterns.

A positive relationship between species richness and available energy is another commonly observed pattern (Currie, 1991; van Rensburg et al., 2002; Bonn et al., 2004; Koh et al., 2006), although some controversy exists about the mechanisms accounting for such a relationship (cf. Rosenzweig \& Abramsky, 1993; Wright et al., 1993; Srivastava \& Lawton, 1998; Waide et al., 1999). In a previous study on South African birds, van Rensburg et al. (2002) indicated that, after examining several environmental variables, the spatially structured component of the variation in the environmental variables, specifically energy availability, accounted for most of the variation in species richness patterns. Chown et al. (2003) also highlighted that areas with high human density and avian species richness values show high levels of spatial congruence across South Africa due to similar responses of humans and avifauna to net primary productivity (for similar conclusions elsewhere see Balmford et al., 2001). Consequently, priority conservation areas are expected to face increased socioeconomic pressures associated with large and growing human populations. While such studies may give a useful indication of the size of future conservation conflicts concerning birds in general, they are limited by uncertainty as to how different taxonomic groups, habitat-specific species and individual species react to anthropogenic pressures.

Using an integrated approach, we examined the relationships between bird species richness (from selected orders), energy availability, anthropogenic activities and spatial autocorrelation. We are aware that when measuring the fraction of variation in species data explained simultaneously by more than one predictor variable, the results should be interpreted with caution (Borcard et al., 1992; Legendre, 1993). Nevertheless, several studies have achieved this successfully after including three predictor components: mainly environmental and spatial influences together with human activity (Barbosa et al., 2001; Real et al., 2003; cf. Vaughn \& Taylor, 2000). Our aim is thus to assess simultaneously the relative importance of environmental, human and spatial influences, as well as the importance of combined influences, between the respective predictor groups, on species richness patterns of different avifaunal orders in South Africa.

\section{METHODS}

\section{Study area}

For the purpose of our study, we considered South Africa a suitable study area due to the availability of comprehensive data on bird distribution and human activity, as well as appropriate environmental data. To determine the relationships between avian species richness and environmental, human and spatial variables, we used the finest national scale data available: the quarter-degree grid cell resolution $\left(15^{\prime} \times 15^{\prime}\right.$, QDC). Grid cells that included land and ocean surfaces simultaneously were eliminated from the data set, resulting in 1795 cells considered for analysis. For each QDC, data were obtained on biotic and abiotic variables.

The Southern African Bird Atlas Project (SABAP; Harrison et al., 1997), which summarizes information on reporting rates of species at the QDC resolution, provided the most comprehensive information available on southern African bird distributions. Using SABAP data, the number of bird species within each of the 1795 QDCs was determined. Those species that are deemed insignificant for South African terrestrial conservation purposes (marine, vagrant, marginal and introduced species) were not included. Only avifaunal orders containing 12 or more species were analysed (Table 1), resulting in a total of 602 species analysed, as they were considered to be more representative of the study area examined.

Biological data collected over large spatial and temporal scales often suffer from survey biases: high survey intensity along roads and close to city centres, and low intensity in more isolated areas (Blackburn \& Gaston, 2002; Rouget et al., 2004). To reduce spurious data collection to some extent, the SABAP opted for standardized and spatially representative collection 
Table 1 Percentage deviance in each species richness group explained by exclusive environmental influences $(E)$, exclusive human influences $(H)$, and exclusive spatial influences $(S)$, as well as proportions of richness explained by environment and space interactions $(E S)$, environment and human interactions $(E H)$, human and space interactions $(H S)$ and interactions between the three predictor groups combined (EHS).

\begin{tabular}{|c|c|c|c|c|c|c|c|c|c|c|}
\hline & E & $H$ & $S$ & $S 1$ & $S 2$ & ES & $E H$ & $H S$ & EHS & Total \\
\hline Coraciiformes & 1.5 & 1.4 & 17.1 & 2.1 & 5.8 & 50.5 & 3.7 & 4.4 & 1.3 & 77.6 \\
\hline Piciformes & 3.1 & 2.4 & 13.2 & 1.4 & 5.8 & 42.3 & 0.0 & 3.1 & 6.0 & 73.3 \\
\hline Passeriformes & 4.8 & 2.7 & 15.5 & 0.5 & 5.5 & 34.6 & 0.0 & 1.8 & 8.6 & 72.6 \\
\hline Galliformes & 1.9 & 3.1 & 15.4 & 0.8 & 3.7 & 31.5 & 0.3 & 7.3 & 1.3 & 62.3 \\
\hline Cuculiformes & 4.0 & 3.0 & 9.9 & 1.1 & 5.2 & 37.9 & 0.0 & 3.0 & 0.5 & 62.2 \\
\hline Falconiformes & 3.4 & 4.4 & 9.2 & 2.1 & 3.5 & 34.1 & 0.0 & 2.4 & 0.8 & 57.7 \\
\hline Collumbiformes & 7.1 & 2.8 & 6.7 & 0.7 & 4.3 & 27.0 & 0.9 & 0.5 & 9.6 & 54.4 \\
\hline Charadriiformes & 7.1 & 3.8 & 10.8 & 1.6 & 4.5 & 5.9 & 6.4 & 10.0 & 3.8 & 48.4 \\
\hline Strigiformes & 1.5 & 3.9 & 6.9 & 0.9 & 1.3 & 28.6 & 0.6 & 3.8 & 0.7 & 46.8 \\
\hline Anseriformes & 0.8 & 2.6 & 11.7 & 0.7 & 5.8 & 13.6 & 1.2 & 6.6 & 10.2 & 46.7 \\
\hline Ciconiformes & 3.8 & 1.6 & 12.4 & 1.5 & 8.1 & 14.5 & 1.2 & 5.0 & 7.5 & 46.0 \\
\hline Gruiformes & 1.0 & 4.7 & 9.0 & 1.6 & 2.7 & 17.0 & 1.1 & 1.5 & 7.8 & 41.9 \\
\hline
\end{tabular}

$S 1$ and $S 2$ are explained in the text and represent components of pure spatial deviance. Bold values denote the predictor group(s) that explain most of the species richness variation in each order.

efforts over South Africa (Harrison et al., 1997). Allan et al. (1997b) showed that survey bias in the SABAP is statistically insignificant. In addition, Evans et al. (2006) concluded that sampling effort in the respective QDCs did not alter the strength of the species richness-human relationship after the results from two different SABAP data sets representing different sampling efforts were compared. These data have been used successfully to address several macro-ecological questions (van Rensburg et al., 2002; Bonn et al., 2004; Lennon et al., 2004).

Our analysis estimated the effects of environmental, anthropogenic (human) and spatial variables in affecting bird species diversity using a variance partitioning procedure pioneered by Whittaker (1984). This procedure has subsequently been adapted for different types of data using sums of squares from stepwise regression analysis (Real et al., 2003); canonical eigenvalues from canonical correlation analysis (Borcard et al., 1992); and deviance values from generalized linear models (GzLM; Lobo et al., 2002).

\section{Environmental factors (Env)}

Van Rensburg et al. (2002) found that net primary productivity (NPP); precipitation (PPT, which is also strongly correlated with NPP); absolute minimum temperature (MIN); and, at coarser resolutions, habitat heterogeneity (VEG) are significant positive correlates of avian species richness in South Africa. For our analysis, we included the same variables. However, as topography has often been identified as an important explanatory variable for species richness patterns (Owen, 1990; Allan et al., 1997a; Patterson et al., 1998), we also included altitudinal range (maximum height a.s.l. minus minimum height a.s.l., in metres) derived from standard 1:250,000 topographical information for South Africa (South African Surveyor General, 2004).

\section{Human activity (Hum)}

Human population density, economic prosperity and land transformation, often used in the literature as surrogates for measuring anthropogenic impact on natural areas (Kerr \& Currie, 1995; Naidoo \& Adamowicz, 2001; Harcourt \& Parks, 2003; Reyers, 2004), were used as indicators of human activity. The 1996 South African population census data (Statistics South Africa, 1998) were used to estimate the density of humans (number of people per $\mathrm{km}^{2}$ ) in each QDC. The average gross income per capita (the remuneration received from all economic activities per capita; Statistics South Africa, 1995), and poverty (considered as the proportion of the population earning less than ZAR200 per month; Statistics South Africa, 1998) were obtained for each QDC. Finally, the extent of land transformation was obtained by calculating and summing the percentage of each land-cover class in each QDC, based on the six transformed land-cover classes identified by Fairbanks \& Thompson (1996) and Fairbanks et al. (2000). These classes are based on seasonally standardized Landsat Thematic Mapper satellite imagery captured primarily during 1994-95, and included anthropogenic effects such as forest plantations, artificial water bodies, urban/built-up areas, cultivated lands, degraded land as well as mines/quarries. For coordination with avian distribution and environmental data, all human activity data were converted to a spatial scale at the QDC level using ArcVIEw GIS 3.2 (ESRI Inc., Redlands, CA, USA) - all human activity data thus represent weighed averages/QDC.

\section{Spatial situation (Spa) including linearity and degree of patchiness characteristics}

Nine different spatial variables were used to measure the influence of spatial autocorrelation on species richness 
patterns. Longitude (Lo), latitude (La) and LoLa describe linear spatial trends, while the other six variables of a cubic trend-surface polynomial of both spatial terms $\left(\mathrm{Lo}^{2}, \mathrm{La}^{2}, \mathrm{Lo}^{3}\right.$, $\left.\mathrm{La}^{3}, \mathrm{Lo}^{2} \mathrm{La}, \mathrm{LoLa}^{2}\right)$ are sufficient to extract more complex features (or patterns) such as patches or gaps of diversity (Borcard et al., 1992; Legendre, 1993; van Rensburg et al., 2002; Real et al., 2003).

\section{Data analysis}

Statistical analyses were conducted using STATistica ver. 6 (StatSoft Inc., Tulsa, OK, USA). For each avifaunal order, analyses using GzLM (McCullagh \& Nelder, 1989) were used to determine the amount of variation in species richness attributable to each of the different predictor groups. The analyses were performed using a Poisson error structure and a logarithmic link function (examination of the residuals revealed that the correct error distribution was used) (for analysis when using count data see Blackburn \& Duncan, 2001; Maggini et al., 2002). To account for overdispersion (Agresti, 1996), the deviance statistic/df values were examined and, where needed, standard errors were scaled using the deviance values as an estimate of the dispersion parameter.

To assess the relationships between species richness and the various predictor groups, the deviance statistic (a measure of goodness of fit for each model) and the percentage deviation explained for the best fitting model were calculated (McCullagh \& Nelder, 1989; Collet, 1991; Dobson, 2002) using the formula:

$$
\begin{aligned}
& \% \text { deviance explained }=[\text { (null deviance statistic }- \text { full } \\
& \text { deviance statistic }) / \text { null deviance statistic }] \times 100
\end{aligned}
$$

Before the GzLM was performed, the effects of possible collinearity between the different predictor variables were taken into account. This is a concern when applying explanatory models where each collinear variable in the logarithmic function has its own explanation rationale. To detect collinearity, the tolerance value for each predictor variable was examined. Tolerance could be defined as 1 minus the squared multiple correlation of a predictor variable with all other independent variables in the regression equation (Statsoft, Inc., 1999); the lower the tolerance of a given variable, the stronger the correlation between the variable in question and one or more of the other predictors. Following Quinn \& Keough (2002), those variables with tolerance values $<0.1$ were eliminated from subsequent analyses. None of the predictor variables was shown to be redundant due to collinearity. However, the spatial variables were not subjected to collinearity tests as the current spatial model attempts to capture maximum species richness variation; eliminating spatial variables would jeopardize this purpose. The relative importance or contribution of each predictor group exclusively, as well as interactions between these groups (e.g. between space and human influence, indicating how human influence that is in itself spatially structured explains species richness patterns) were estimated, following three steps. First, we determined the amount of deviation explained by the three groups of predictor variables simultaneously (Env $\cup$ Hum $\cup$ Spa): each avifaunal group's species richness was regressed onto all the variables together (the full model). This provided an indication of the total amount of deviation explained by all the variables simultaneously. Second, we determined the degree to which each of the three individual groups of predictor variables (Env, Hum and Spa) explains geographical species richness patterns within each avian order. Spatial data for each order were regressed against the variables within each group of predictor variables. Third, we estimated the sizes of the components of each of the main sets of predictor variables (Fig. 1). Predictor variables may counteract or have additive effects on one another (Borcard et al., 1992). Therefore we can expect a difference between the total amount of deviation of species richness explained by the three explanatory groups combined (Env $\cup$ Hum $\cup$ Spa from step 1 above), and the sum of the amounts of variation of species richness that can be explained by each of the three groups in isolation $(\mathrm{Env}+\mathrm{Hum}+\mathrm{Spa}$ from step 2). Thus the variation in each avian group's species richness was divided into two components: (a) that due to a predictor group exclusively (components $E, H$ and $S$ in Fig. 1); (b) interactions between the three different predictor groups (components SE, SH, EH and ESH in Fig. 1). The effect of spatial predictor variables excluding all interaction $(S)$ was estimated by calculating the deviation explained by human activity and environmental variables together (the union Env $\cup$ Hum, obtained by regressing species richness onto the environmental (Env) and human (Hum) variables simultaneously. Following Real et al.'s (2003) variance-partitioning procedure, the proportion of the variation explained exclusively by the spatial variables $(S)$ was obtained with the

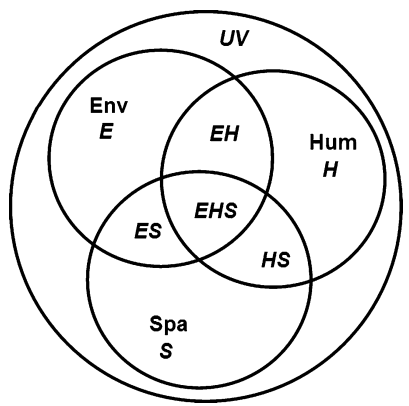

Figure 1 Diagram indicating the components of each predictor group exclusively, as well as interactions between these groups, in explaining avian species richness patterns. Spa $=$ spatial autocorrelation; Hum = human activity; Env = environmental conditions. $E, H$ and $S$ are the exclusive effects of environmental conditions, human activity and spatial autocorrelation, respectively. ES, EH, HS and EHS represent the interactions between environment and space, between environment and human activity, between human activity and space, and finally between all three predictor variables. $U V$ represents the unexplained variation. 


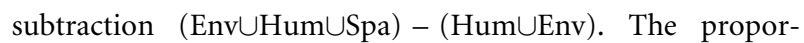
tions explained exclusively by humans $(H)$ and exclusively by environment $(E)$, respectively, were obtained in a similar fashion. To assess the influence of interactions between environment and human activity $(E H)$ on species richness patterns, the simultaneous influence of these predictor variables was calculated with the subtraction (Env $\cup$ Hum $\cup$ Spa) - Spa $-E-H$. The interactions between humans and space $(H S)$ and between environment and space (ES) were obtained similarly. Finally, the extent to which interactions among all three groups of predictor variables $(E H S)$ contributed towards spatial variation in species richness was obtained using the subtraction (Env $\cup$ Hum $\cup$ Spa) $-E-H-S-E H-E S-H S$.

A subsidiary analysis was performed to estimate the separate effects of the linear components of spatial variation (the firstorder terms among the spatial variables that explain linear trends such as large-scale rainfall gradients) and the higherorder terms (that describe nonlinear geographical structures such as patchiness of populations). This was performed by subdividing Spa into two components: Spal (linear) and Spa2 (higher-order). As for the other predictor variables described above, the degree to which Spa1 and Spa2 were related to richness patterns was estimated by regressing them onto geographical diversity patterns for each avian order. For excluding interactions that Spal and Spa2 have with other variables, the corresponding spatial variables that exclude any interactions were calculated as: $S 1=($ Env $\cup$ Hum $\cup S p a 1 \cup S p a 2)$ - Hum - Env - Spa2. The corresponding value S2 was estimated in a similar way.

Finally, to investigate further the patterns in water-living bird species related to anthropogenic activities, we raised the question of the extent to which and the direction in which these species are being affected by artificial water bodies at the broad regional scale. To do this, we compared the effect of the total surface area covered by water bodies $\left(\mathrm{km}^{2}\right)$ on threatened and non-threatened water species richness in statistical models that did and did not take artificial water into account. Relationships were examined using two sAs ver. 9.1 procedures (SAS Institute Inc., Cary, USA): PROC GLM (assuming independent errors) to implement general linear models; and PROC MIXED to take spatial autocorrelation into account (for more information on how this procedure fits a spatial covariance matrix to the data, see Littell et al., 1996). To reduce heteroscedasticity, species richness values and percentage of water body areas were logarithmically transformed to base 10. This was achieved after adding values of one to each variable in order to best transform all zero numbers.

\section{RESULTS}

Spatially structured environmental deviance (ES) explained most of the deviance in species richness across 11 of the 12 avifaunal orders examined (averaging 28\%; SD 13\%), followed by purely spatial deviance ( $S$, averaging $12 \%$; SD $3 \%$ ) (Table 1). From the bivariate human relationship and all combinations examined (excluding $E H S$ ), spatially structured human impacts (HS) accounted for most deviance, although this explanatory power was very low (averaging 4\%; SD 3\%). This factor together with pure spatial deviance did, however, explain $21 \%$ of the species richness variation in the order Charadriiformes (Table 1).

Of the total deviance in species richness explained by the variables included in the model, spatially structured environmental factors explained $50 \%$ or more of the deviance in seven of the 12 orders examined (Table 1). Of these, Coraciiformes, Cuculiformes and Strigiformes showed the highest percentage values $(65,61$ and 61 , respectively). In the case of the order Charadriiformes, where purely spatial deviance accounted for most of the deviance, $22 \%$ of its deviance was accounted for by this factor (Table 1).

Although some general trends were similar among the different bird orders (e.g. the dominance of spatially structured variables in describing bird species richness), clear differences in pattern were also evident among the orders. First, the proportion of the total deviance for each order explained by the variables included in the model varied $(42-78 \%$, averaging 57\%; SD 12\%; Table 1). This means that the model used provided a much better fit for some orders, while being somewhat less successful for others. For the water birds (Charadriiformes: waders; Anseriformes: waterfowl; Ciconiformes: herons and storks; Gruiformes: cranes and rails), the model explained $<50 \%$ of the total deviance.

Second, three of the four orders comprising mostly water birds (Charadriiformes, Anseriformes, Ciconiformes) have a relatively large component of purely spatial deviance compared with spatially structured environmental deviance (Table 1). For instance, the purely spatial deviance for the Charadriiformes is larger than the spatially structured environmental deviance. In the case of the Anseriformes and the Ciconiformes, these two sources of deviance were almost of equal size. The Gruiformes and Galliformes have an intermediate position in this respect, with pure spatial deviance being about half the magnitude for spatially structured environmental deviance. In the other taxa, the spatially structured environmental deviance is substantially larger than the purely spatial deviance.

Third, the Charadriiformes and Anseriformes had a relatively important component of spatially structured human deviance, accounting for $21 \%$ and $14 \%$, respectively, of their total deviances. The other water bird orders (Gruiformes and Ciconiformes) have a low-to-intermediate position in comparison with the remaining orders. The comparatively important component of spatial congruence between anthropogenic activities and water-living bird species therefore complements the additional analysis to better understand the extent to which these species are being affected by the total area covered by artificial water bodies. Both before and after taking artificial water bodies into account, the statistical estimates of the slopes of the species-natural water relationships remained extremely weak (Tables $2 \& 3$ ). This consistency was evident from both the independent error models and spatial models showing no significant differences when comparing the slopes' 95\% confidence intervals (Table 4). The independent error model 
Bird, human and environmental interactions

Table 2 Effect of natural water bodies on water-living bird species richness in South Africa in univariate tests.

\begin{tabular}{lllll}
\hline Response & Model & $\begin{array}{l}\log _{10} \text { natural } \\
\text { water }(\%)\end{array}$ & $\begin{array}{l}\left(\log _{10} \text { natural }\right. \\
\text { water })^{2}(\%)\end{array}$ & Model fit \\
\hline Threatened water bird species & GLM & $F_{1,1791}=1.90+\mathrm{ns}$ & $F_{1,1791}=0.17+\mathrm{ns}$ & $r^{2}=0.015$ \\
& Spatial & $F_{1,1791}=4.92+$ & $F_{1,1791}=0.09-\mathrm{ns}$ & AIC $=-411.8$ \\
Non-threatened water bird species & GLM & $F_{1,1791}=2.36+\mathrm{ns}$ & $\begin{array}{l}F_{1,1791}=0.01+\mathrm{ns} \\
r^{2}=0.013\end{array}$ \\
& Spatial & $F_{1,1791}=6.78++$ & $F_{1,1791}=0.02-\mathrm{ns}$ & AIC $=-357.5$ \\
\hline
\end{tabular}

Positive effects: $+\mathrm{ns}, P \geq 0.05 ;+, P<0.05 ;++, P<0.01$; negative effects: $-\mathrm{ns}, P \geq 0.05$.

General linear models assumed independent errors, spatial models accounted for spatial autocorrelation. $F$ ratios and associated significance levels are provided. Akaike's information criterion (AIC) values were used to assess the fit of spatial models. The model selection process was based on the lowest AIC value, as smaller values indicate a better fit. Response and predictor variables were logarithmically transformed prior to analysis.

Table 3 Minimum adequate models of water bird species-water relationships that control for artificial water bodies.

\begin{tabular}{|c|c|c|c|c|c|c|}
\hline Response & Model & $\begin{array}{l}\log _{10} \\
\text { natural } \\
\text { water }(\%)\end{array}$ & $\begin{array}{l}\left(\log _{10} \text { natural }\right. \\
\text { water })^{2}(\%)\end{array}$ & $\begin{array}{l}\log _{10} \text { artificial } \\
\text { water (\%) }\end{array}$ & $\begin{array}{l}\left(\log _{10} \text { artificial }\right. \\
\text { water })^{2}(\%)\end{array}$ & Model fit \\
\hline \multirow{4}{*}{$\begin{array}{l}\text { Threatened water } \\
\text { bird species } \\
\text { Non-threatened water } \\
\text { bird species }\end{array}$} & GLM & $F_{1,1789}=1.92+\mathrm{ns}$ & $F_{1,1789}=0.17+\mathrm{ns}$ & $F_{1,1789}=33.60++++$ & $F_{1,1789}=8.66--$ & $r^{2}=0.043$ \\
\hline & Spatial & $F_{1,1789}=5.07+$ & $F_{1,1789}=0.10-\mathrm{ns}$ & $F_{1,1789}=7.94++$ & $F_{1,1789}=1.47-\mathrm{ns}$ & $\mathrm{AIC}=-419.2$ \\
\hline & GLM & $F_{1,1789}=2.59+\mathrm{ns}$ & $F_{1,1789}=0.01+\mathrm{ns}$ & $F_{1,1789}=96.89++++$ & $F_{1,1789}=34.68----$ & $r^{2}=0.077$ \\
\hline & Spatial & $F_{1,1789}=7.10++$ & $F_{1,1789}=0.03-\mathrm{ns}$ & $F_{1,1789}=29.97++++$ & $F_{1,1789}=9.38--$ & $\mathrm{AIC}=-392.5$ \\
\hline
\end{tabular}

Positive effects: + ns, $P \geq 0.05 ;+, P<0.05 ;++, P<0.01 ;++++, P<0.0001$; negative effects: - ns, $P \geq 0.05 ;--, P<0.01 ;----, P<0.0001$. General linear models assumed independent errors, spatial models accounted for spatial autocorrelation. $F$ ratios and associated significance levels are provided. Akaike's information criterion (AIC) values were used to assess the fit of spatial models. The model selection process was based on the lowest AIC value, as smaller values indicate a better fit. Response and predictor variables were logarithmically transformed prior to analysis.

Table 4 Estimates of the slopes of water bird species-water relationships (95\% CI) obtained from univariate models and those that take artificial water bodies into account.

\begin{tabular}{|c|c|c|c|c|c|}
\hline \multirow[b]{2}{*}{ Response } & \multirow[b]{2}{*}{ Model } & \multicolumn{2}{|c|}{ Estimate of slope without artificial water } & \multicolumn{2}{|c|}{ Estimate of slope with artificial water } \\
\hline & & $\begin{array}{l}\log _{10} \text { natural } \\
\text { water }(\%)\end{array}$ & $\begin{array}{l}\left(\log _{10} \text { natural }\right. \\
\text { water })^{2}(\%)\end{array}$ & $\begin{array}{l}\log _{10} \text { natural } \\
\text { water }(\%)\end{array}$ & $\begin{array}{l}\left(\log _{10} \text { natural }\right. \\
\text { water })^{2}(\%)\end{array}$ \\
\hline \multirow[t]{2}{*}{ Threatened water bird species } & GLM & -0.045 to 0.260 & -0.100 to 0.153 & -0.044 to 0.257 & -0.098 to 0.151 \\
\hline & Spatial & 0.016 to 0.254 & -0.110 to 0.081 & 0.018 to 0.255 & -0.111 to 0.079 \\
\hline \multirow[t]{2}{*}{ Non-threatened water bird species } & GLM & -0.039 to 0.316 & -0.142 to 0.152 & -0.031 to 0.312 & -0.140 to 0.143 \\
\hline & Spatial & 0.039 to 0.278 & -0.103 to 0.089 & 0.042 to 0.279 & -0.104 to 0.086 \\
\hline
\end{tabular}

General linear models assumed independent errors, spatial models accounted for spatial autocorrelation.

and the spatial model suggested that, compared with natural water bodies, spatial patterns in artificial water bodies were stronger and more significantly related to the richness patterns of water birds (Table 3), although the overall amount of variance explained by the water bodies was low. While nonthreatened species richness patterns seem to be stronger and more significantly related to artificial water bodies compared with threatened species (Table 3), the overall results, at least at the broad spatial resolution of QDC, seem to indicate that artificial water bodies were having a positive influence on water bird species richness.

With purely spatial variation accounting for a significant amount of deviance among water birds, the question arises as to how much of this spatial deviance is due to linear gradients in species richness $(S 1)$, as opposed to higher-order spatial effects such as patchiness (S2). Understanding the nature of such spatial deviance could be relevant when assessing how human activity may alter natural species richness patterns. In all the avian orders examined, the higher-order spatial effects were larger than the gradient effects (Table 1). Especially for the water birds, the higher-order spatial effects tended to be relatively much larger than the linear effects, although they did not differ quantitatively from the remaining orders. Spatial autocorrelation due to higher-order spatial effects were therefore important, indicating relatively large degrees of complex spatial patterns in bird richness across all orders. The combined values of the linear $(S 1)$ and higher-order sources (S2) of purely spatial deviance were much lower than the 
combined purely spatial deviance $(S)$ (Table 1$)$. This suggests a significant interaction between the linear and nonlinear components of pure spatial variation, $S 1 \cap S 2$.

Finally, to assess whether the variation in total number of species across the avian groups influenced the percentage deviance in richness explained by the different predictor groups, we used linear and nonlinear regressions to investigate the relationships between species richness (including all avian groups examined) and the explanatory power of each predictor group, respectively. Relationships were weak (correlation coefficients varying between -0.30 and 0.19 ) and non-significant ( $P$ values varying between 0.14 and 0.94 ). Curvilinear relationships did not improve the fit of the models. These results therefore suggest that the variation in total species number across avian groups had no significant influence on the explanatory power found for the different predictor groups used.

\section{DISCUSSION}

Spatially structured environmental deviance accounted for most of the variation exhibited in avian bird orders at the scale of QDC in South Africa, when compared with measures of human activity. This result is consistent with previous studies conducted at this (regional) scale on overall bird species richness patterns in South Africa (van Rensburg et al., 2004b) and other taxa elsewhere (Barbosa et al., 2001; Real et al., 2003). Even after examining a highly transformed region within South Africa, it was concluded that biogeographical patterns in birds can be recovered using modern data, despite landscape transformation (for explanations as to why this may be true, see van Rensburg et al., 2004b and references therein).

Much of this covariation between richness and the environmental variables is a consequence of the strong east-west gradient in precipitation, and associated gradients in both productivity and vegetation heterogeneity across South Africa (Schulze, 1997a,b) to which species richness patterns respond positively (e.g. mammals, Andrews \& O'Brien, 2000; plants, O'Brien et al., 2000; birds, van Rensburg et al., 2002). This undoubtedly also explains the small proportion of richness accounted for solely by the environment (a common feature of regional-scale studies; Borcard et al., 1992).

\section{Spatial effects on species richness of water birds}

Perhaps more interestingly, compared with all the avian orders examined, it is clear that the variation accounted for solely by space indicates that the three orders comprising mostly water birds (Charadriiformes, Anseriformes and Ciconiformes) show significant spatial autocorrelation independent of the spatial structure of the explanatory variable in question. This was true especially for Charadriiformes, where the pure spatial deviance component was larger than the environmentally structured spatial deviance (Table 1). Our study suggests that the spatial autocorrelation within the avian species richness patterns was characterized mostly by higher-order spatial effects ('spatial clumpedness') as opposed to linear gradients, indicating more complex patterns (e.g. patchy or humped-shaped distributions; Borcard et al., 1992; Legendre, 1993), especially in species richness of birds that are directly related to water sources (water-living bird orders). The complex and highly spatially autocorrelated richness patterns in water birds are probably a reflection of the spatial distribution of natural and humanmade water bodies in a relatively arid region. That is, both are showing higher-order spatial effects describing a nonlinear geographical structure such as a patchy (S2) distribution across the South African landscape (Fairbanks \& Thompson, 1996; Fairbanks et al., 2000).

\section{Anthropogenic effects on species richness of water birds}

The idea of significant anthropogenic effects, especially on water-related birds, was supported further with human structured spatial deviance being an important component in explaining variation in Charadriiformes and Anseriformes richness patterns when compared with all avian orders examined (Table 1). Different species react differently to the same predictor variable. For example, many so-called 'weedy' taxa (Harcourt \& Parks, 2003) benefit from human activities and consequently occur in high densities in altered areas, which are otherwise unoccupied by species sensitive to human activities. Avifaunal assemblages in built-up areas are often dominated by introduced species such as the common myna (Acridotheres tristis), the house sparrow (Passer domesticus) and the rock dove (Columba livia) (e.g. Hockey et al., 2005), while many threatened bird species rarely enter such areas (Barnes, 2000). This interaction between positively and negatively influenced species might conceal the true extent of human activity on biodiversity. Through the creation of various artificial water bodies in areas devoid of water, human activity allowed many Charadriiform species (more resilient species and those not threatened) to colonize areas that would otherwise be unoccupied (Harrison et al., 1997; Fairbanks et al., 2002; Hockey et al., 2005). Consistent with this idea, the results from our study suggested a positive and significant relationship, albeit weak, at the broad regional scale between the spatial distribution of artificial water bodies and richness patterns of both threatened and unthreatened water birds.

Several more detailed studies conducted at the finer local scale have shown that, at least from an avian conservation perspective, the negative consequences of natural water bodies being transformed outweigh those positive interactions related to artificial water bodies being created. For example, three of South Africa's five critically endangered bird species are threatened mainly by the destruction of suitable wetlands, for example through creation of dams and intensified agriculture (Barnes, 2000). Furthermore, most species that benefit from, or are associated with, artificial water bodies are not threatened (Hockey et al., 2005). Artificial water bodies therefore contribute little to the conservation of the region's avifauna. With future water availability likely to decline in 
South Africa (Schulze et al., 2001; Erasmus et al., 2002), subsequent resources and conservation conflicts are likely to escalate across most, if not all, the avian orders examined (for African mammal extinctions see Ceballos \& Ehrlich, 2002; for taxa worldwide see http://www.iucnredlist.org). That is, fewer areas across South Africa, and probably also across the rest of Africa (Balmford et al., 2001) and other regions, will be able to harbour both high species richness and greater human population densities than is presently the case (van Rensburg et al., 2004a; cf. Koh et al., 2006). Such a scenario will increasingly threaten species in the order Charadriiformes that are highly dependent on water to maintain viable populations. This is true even for those species currently favourably influenced by artificial water bodies, due to knock-on effects on biodiversity such as human demand for agricultural resources, especially water, as the human population continues to grow (Tilman et al., 2001).

Compared with all the avian orders examined, purely human activities explained most of the diversity distribution for Gruiformes, which also contains the highest proportion (48\%) of threatened species (e.g. the white-winged flufftail, Sarothrura ayresi and the wattled crane, Grus carunculatus; Barnes, 2000). The order Gruiformes is known to be sensitive to human-induced habitat loss, and many members face extinction in the near future due to this threat (Harrison et al., 1997; Barnes, 2000; Hockey et al., 2005). However, the variation accounted for by human activity (5\%) was generally small compared with the spatially structured environmental variation component (17\%). This is probably attributed to the low proportion of total deviance for Gruiformes species richness explained by the variables included in the model (42\%; Table 1). This high unexplained variation (highest for all orders examined) is attributed to factors not considered in our study mainly as a result of its coarse spatial scale. Several factors identified as primary limiting factors in determining local bird distributions, and known to be influenced by humans, were not taken into account, such as food availability and habitat quality or structure. The idea of fine-scale explanatory variables not being captured in the models was supported by a general decrease in the total deviance explained for each order as the importance of the environmentally structured spatial deviance became less of an explanatory factor; the environmental component consisted mainly of climatic variables known to explain richness patterns at the regional scale (Currie, 1991).

\section{Spatial patterns in species richness of savanna and forest birds}

More generally, compared with all the orders examined, deviance in spatial patterns of the order Coraciiformes was best explained by all the combined variables included in the model, as well as for spatially structured environmental deviance only. Species within this order, for example kingfishers, bee-eaters and hornbills, are known to be strongly associated with savanna and forest habitats dominated by trees (Hockey et al.,
2005). At least for South Africa, tree richness is known to be highly positively correlated with environmental variables, particularly with a water-energy model (O'Brien et al., 2000; O'Brien, 2006). Although all the avian orders examined had lower $S 1$ values (linear gradients in richness values) than $S 2$ values (more complex richness values), the ratio between $S 1$ and $S 2$ was $<1: 2$ for three of the 12 bird orders examined. Such a result suggests that these three orders (Falconiformes, including birds of prey; Strigiformes, owls; Gruiformes, cranes, korhaans, bustards and flufftails) also tend to show some strong component of linear gradients in their richness patterns. It is interesting to note that two of the three orders constitute raptor species; we are not sure what the explanation for this is. Raptors generally have a large body size (Hockey et al., 2005) resulting in Falconiformes and Strigiformes being characterized, on average, with larger body sizes compared with the other bird orders examined. Generally, it is known that largerbodied species tend to have larger, and therefore more continuous, range sizes compared with smaller-bodied species (reviewed by Gaston \& Blackburn, 1996), and a concentration of such distribution patterns among species within a single bird order could favour a more linear gradient in species richness values compared with more complex richness values.

In conclusion, we found clear differences in the extent to which different avian orders are related to environmental, human and spatial variables, either combined or exclusively. Although it has been suggested that models developed at crude spatial resolutions (such as this study) must be interpreted cautiously as they do not adequately capture finer-scale predictor variables, we have demonstrated clearly that, at the broad scale, bird species richness patterns across South Africa are complex and patchy across all orders. These complex patterns became apparent especially in Charadriiformes (and to a lesser degree the remaining orders representing water birds) even in the absence of any predictor variables. Our results, however, suggest that a large amount of the complex spatial variation in the species richness of these water bird orders can be attributed to human influences, mostly with negative conservation consequences.

\section{ACKNOWLEDGEMENTS}

Thanks to Duan Biggs and Faansie Peacock for sharing much of their birding expertise, as well as Lindie Janse van Rensburg and Marie Warren for valuable discussion. The input of some anonymous referees and the handling editor greatly improved the manuscript. The Avian Demography Unit, University of Cape Town provided bird distribution data, while the National Research Foundation and the University of Pretoria provided financial support. B.J.V.R. acknowledges support from the DST-NRF Centre of Excellence for Invasion Biology.

\section{REFERENCES}

Agresti, A. (1996) An introduction to categorical data analysis. Wiley, New York. 
Allan, D.G., Harrison, J.A., Herremans, M., Navarro, R.A. \& Underhill, L.G.(1997a) South African geography: its relevance to birds. The atlas of southern African birds (ed. by J.A. Harrison, D.G. Allan, L.G. Underhill, M. Herremans, V. Parker and C.J. Brown), Vol. 1, pp. 1xv-ci. Birdlife South Africa, Johannesburg.

Allan, D.G., Harrison, J.A., van Wilgen, B.W. \& Thompson, M. (1997b) The impact of commercial afforestation on bird populations in the Mpumalanga province, South Africa insights from bird atlas data. Biological Conservation, 79, 173-185.

Andrews, P. \& O’Brien, E.M. (2000) Climate, vegetation, and predictable gradients in mammal species richness in southern Africa. Journal of Zoology, 251, 205-231.

Balmford, A., Moore, J.L., Brooks, T., Burgess, N., Hansen, L.A., Williams, P. \& Rahbek, C. (2001) Conservation conflicts across Africa. Science, 291, 2616-2619.

Barbosa, A.M., Real, R., Márquez, A.L. \& Rendón, M.A. (2001) Spatial, environmental and human influences on the distribution of otter (Lutra lutra) in the Spanish provinces. Diversity and Distributions, 7, 137-144.

Barnes, K.N. (2000) The Eskom red data book of birds of South Africa, Lesotho and Swaziland. Birdlife South Africa, Johannesburg.

Blackburn, T.M. \& Duncan, R.P. (2001) Establishment patterns of exotic birds are constrained by non-random patterns in introduction. Journal of Biogeography, 28, 927-939.

Blackburn, T.M. \& Gaston, K.J. (2002) Scale in macroecology. Global Ecology and Biogeography, 11, 185-189.

Bonn, A., Storch, D. \& Gaston, K.J. (2004) Structure of the species-energy relationship. Proceedings of the Royal Society B: Biological Sciences, 271, 1685-1691.

Borcard, D., Legendre, P. \& Drapeau, P. (1992) Partialling out the spatial component of ecological variation. Ecology, 73, 1045-1055.

Ceballos, G. \& Ehrlich, P.R. (2002) Mammal population losses and the extinction crisis. Science, 296, 904-907.

Chown, S.L., van Rensburg, B.J., Gaston, K.J., Rodrigues, A.S.L. \& van Jaarsveld, A.S. (2003) Energy, species richness, and human population size: conservation implications at a national scale. Ecological Applications, 13, 1233-1241.

Collet, D. (1991) Modelling binary data. Chapman \& Hall, London.

Currie, D.J. (1991) Energy and large-scale patterns of animaland plant-species richness. The American Naturalist, 137, 27-49.

Diniz-Filho, J.A.F., Bini, L.M. \& Hawkins, B.A. (2003) Spatial autocorrelation and red herrings in geographical ecology. Global Ecology and Biogeography, 12, 53-64.

Dobson, A.J. (2002) An introduction to generalized linear models, 2nd edn. Chapman \& Hall, London; CRC Texts in Statistical Science, Boca Raton, FL.

Erasmus, B.F.N., van Jaarsveld, A.S., Chown, S.L., Kshatriya, M. \& Wessels, K.J. (2002) Vulnerability of South African animal taxa to climate change. Global Change Biology, 8, 679-693.

Evans, K.L., van Rensburg, B.J., Gaston, K.J. \& Chown, S. L. (2006) People, species richness and human population growth. Global Ecology and Biogeography, 15, 625636.

Fairbanks, D.H.K. \& Thompson, M. (1996) The standard land-cover classification scheme for remote sensing application in South Africa. South African Journal of Science, 92, 34-42.

Fairbanks, D.H.K., Thompson, M.W., Vink, D.E., Newby, T., van den Berg, H.M. \& Everard, D.A. (2000) The South African land-cover characteristics database: a synopsis of the landscape. South African Journal of Science, 96, 6986.

Fairbanks, D.H.K., Kshatriya, M., van Jaarsveld, A.S. \& Underhill, L.G. (2002) Scales and consequences of human land transformation on South African avifaunal diversity and structure. Animal Conservation, 5, 61-74.

Gaston, K.J. (2000) Global patterns in biodiversity. Nature, 405, 220-227.

Gaston, K.J. (2005) Biodiversity and extinction: species and people. Progress in Physical Geography, 29, 239-247.

Gaston, K.J. \& Blackburn, T.M. (1996) Conservation implications of geographic range size-body size relationships. Conservation Biology, 10, 638-646.

Gaston, K.J., Rodrigues, A.S.L., van Rensburg, B.J., Koleff, P. \& Chown, S.L. (2001) Complementary representation and zones of ecological transition. Ecology Letters, 4, 4-9.

Harcourt, A.H. \& Parks, S.A. (2003) Threatened primates experience high human densities: adding an index of threat to the IUCN Red List criteria. Biological Conservation, 109, 137-149.

Harrison, J.A., Allan, D.G., Underhill, L.G., Herremans, M., Parker, V. \& Brown, C.J. (1997) The atlas of southern African birds, Vols 1 and 2. Birdlife South Africa, Johannesburg.

Hockey, P.A.R., Dean, W.R.J. \& Ryan, P.G. (eds) (2005) Roberts birds of southern Africa, VIIth edn. Trustees of the John Voelcker Bird Book Fund, Cape Town.

Kerr, J.T. \& Currie, D.J. (1995) Effects of human activity on global extinction risk. Conservation Biology, 9, 15281538.

Koh, C.-N., Lee, P.-F. \& Lin, R.-S. (2006) Bird species richness patterns of northern Taiwan: primary productivity, human population density, and habitat heterogeneity. Diversity and Distributions, 12, 546-554.

Legendre, P. (1993) Spatial autocorrelation: trouble or new paradigm? Ecology, 74, 1657-1673.

Legendre, P. \& Fortin, M.-J. (1989) Spatial pattern and ecological analysis. Vegetatio, 80, 107-138.

Legendre, L. \& Legendre, P. (1998) Interpretation of ecological structures. Numerical ecology, 2nd edn (ed. by L. Legendre and P. Legendre), pp. 481-574. Elsevier, Amsterdam.

Lennon, J.J., Koleff, P., Greenwood, J.J.D. \& Gaston, K.J. (2004) Contribution of rarity and commonness to patterns of species diversity. Ecology Letters, 7, 81-87. 
Littell, R.C., Milliken, G.A., Stroup, W.W. \& Wolfinger, R.D. (1996) SAS system for mixed models. SAS Institute, Cary, NC.

Lobo, J.M., Lumaret, J.P. \& Jay-Robert, P. (2002) Modelling the species richness distribution of French dung beetles (Coleoptera, Scarabaeidae) and delimiting the predictive capacity of different groups of explanatory variables. Global Ecology and Biogeography, 11, 265-277.

Maggini, R., Guisan, A. \& Cherix, D. (2002) A stratified approach for modeling the distribution of a threatened ant species in the Swiss National Park. Biodiversity and Conservation, 11, 2117-2141.

Margules, C.R. \& Pressey, R.L. (2000) Systematic conservation planning. Nature, 405, 243-253.

McCullagh, P. \& Nelder, J.A. (1989) Generalised linear models. Chapman \& Hall, London.

McDonnell, M.J. \& Pickett, S.T.A. (1990) Ecosystem structure and function along urban-rural gradients: an unexploited opportunity in ecology. Ecology, 71, 1232-1237.

Naidoo, R. \& Adamowicz, W.L. (2001) Effects of economic prosperity on numbers of threatened species. Conservation Biology, 15, 1021-1029.

O'Brien, E.M. (1998) Water-energy dymanics, climate, and prediction of woody plant species richness: an interim general model. Journal of Biogeography, 25, 379-398.

O'Brien, E.M. (2006) Biological relativity to water-energy dynamics. Journal of Biogeography, 33, 1868-1888.

O'Brien, E.M., Field, R. \& Whittaker, R.J. (2000) Climatic gradients in woody plant (tree and shrub) diversity: waterenergy dynamics, residual variation, and topography. Oikos, 89, 588-600.

O’Neill, R.V. \& Kahn, J.R. (2000) Homo ecenomus as a keystone species. BioScience, 50, 333-337.

Owen, J.G. (1990) Patterns of mammalian species richness in relation to temperature, productivity, and variance in elevation. Journal of Mammalogy, 71, 1-13.

Patterson, B.D., Stolz, D.F., Solari, S., Fitzpatrick, J.W. \& Pacheco, V. (1998) Contrasting patterns of elevation zonation for birds and mammals in the Andes of southeastern Peru. Journal of Biogeography, 25, 593-607.

Quinn, G.P. \& Keough, M.J. (2002) Experimental design and data analysis for biologists. Cambridge University Press, Cambridge.

Real, R., Barbosa, A.M., Porras, D., Kin, M.S., Márquez, A.L., Guerrero, J.C., Palomo, L.J., Justo, E.R. \& Vargas, J.M. (2003) Relative importance of environment, human activity and spatial situation in determining the distribution of terrestrial mammal diversity in Argentina. Journal of Biogeography, 30, 939-947.

Reyers, B. (2004) Incorporating anthropogenic threats into evaluations of regional biodiversity of conservation areas in the Limpopo Province, South Africa. Biological Conservation, 118, 521-531.

Rosenzweig, M.L. \& Abramsky, Z. (1993) How are diversity and productivity related? Species diversity in ecological communities: historical and geographical perspectives (ed. by R.E.
Ricklefs and D. Schluter), pp. 52-65. University of Chicago Press, Chicago.

Rouget, M., Reyers, B., Jonas, Z., Desmet, P., Driver, A., Maze, K., Egoh, B. \& Cowling, R.M. (2004) South African National Spatial Biodiversity Assessment 2004: Technical report, Vol. 1: terrestrial component. South African National Biodiversity Institute, Pretoria.

Schiegg, K. (2003) Environmental autocorrelation: curse or blessing? Trends in Ecology \& Evolution, 18, 212-214.

Schulze, R.E. (1997a) Climate. Vegetation of southern Africa (ed. by R.M. Cowling, D.M. Richardson and S.M. Pierce), pp. 21-42. Cambridge University Press, Cambridge.

Schulze, R.E. (1997b) South African atlas of agrohydrology and climatology. Report TT82/96. Water Research Commission, Pretoria.

Schulze, R., Meigh, J. \& Horan, M. (2001) Present and potential future vulnerability of eastern and southern Africa's hydrology and water resources. South African Journal of Science, 97, 150-160.

South African Surveyor General (2004) Digital elevation model for South Africa. Department of Land Affairs - Division of Surveying and Mapping, Cape Town.

Srivastava, D.S. \& Lawton, J.H. (1998) Why more productive sites have more species: an experimental test of theory using tree-hole communities. The American Naturalist, 152, 510-529.

Statistics South Africa (1995) Gross geographic product 1994. Statistical release P0401. Central Statistical Service, Pretoria.

Statistics South Africa (1998) Population census 1996. Report no. 03-01-30. Statistics South Africa, Pretoria.

Statsoft, Inc. (1999) Statistica for windows. Statsoft Inc., Tulsa, OK.

Tilman, D., Fargione, J., Wollf, B., D’Antonio, C., Dobson, A., Howarth, R., Schindler, D., Schlesinger, W.H., Simberloff, D. \& Swackhamer, D. (2001) Forecasting agriculturally driven global environmental change. Science, 292, 281-284.

van Rensburg, B.J., Chown, S.L. \& Gaston, K.J. (2002) Species richness, environmental correlates, and spatial scale: a test using South African birds. The American Naturalist, 159, 566-577.

van Rensburg, B.J., Erasmus, B.F.N., van Jaarsveld, A.S., Gaston, K.J. \& Chown, S.L. (2004a) Conservation during times of change: correlations between birds, climate and people in South Africa. South African Journal of Science, 100, 266273.

van Rensburg, B.J., Koleff, P., Gaston, K.J. \& Chown, S.L. (2004b) Spatial congruence of ecological transition at the regional scale in South Africa. Journal of Biogeography, 31, $1-12$.

Vaughn, C.C. \& Taylor, C.M. (2000) Macroecology of a hostparasite relationship. Ecography, 23, 11-20.

Waide, R.B., Willig, M.R., Steiner, C.F., Mittelbach, G., Gough, L., Dobson, S.I., Juday, G.P. \& Parmenter, R. (1999) The relationship between productivity and species richness. Annual Reviews of Ecology and Systematics, 30, 257-300. 
Whittaker, J. (1984) Model interpretation from the additive elements of the likelihood function. Applied Statistics, 33, 52-64.

Wright, D.H., Currie, D.J. \& Maurer, B.A. (1993) Energy supply and patterns of species richness on local and regional scales. Species diversity in ecological communities: historical and geographical perspectives (ed. by R.E. Ricklefs and D. Schluter), pp. 66-74. University of Chicago Press, Chicago, IL.

\section{BIOSKETCHES}

Johnny Wilson is a student in conservation ecology. His research interests revolve around conservation planning in a non-static environment.

Berndt J. van Rensburg is senior lecturer in the Department of Zoology and Entomology, University of Pretoria. He works in the fields of invasion biology, human impacts on biodiversity and macroecology, especially in southern Africa, focusing on conservation planning.

Willem Ferguson is Director of the Centre for Environmental Studies at the University of Pretoria. He has a special interest in grassland conservation and the endemic plants and animals found in that habitat.

Mark Keith's research involves investigating and quantifying threats relating to both plants and animals, trying to assist in understanding modern conservation issues in southern Africa.

Editor: Melodie McGeoch 